\title{
Çeşitli antiseptik taşıyıcılarla karıştırılan kalsiyum hidroksitin Enterococcus faecalis üzerindeki antimikrobiyal etkinliği ${ }^{*}$
}

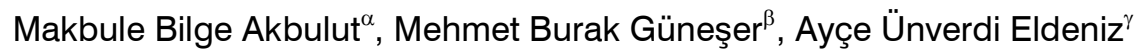

Selcuk Dent J, 2017; 4: 44-51 (Doi: 10.15311/1441.308558)

Başvuru Tarihi: 24 Nisan 2017 Yayına Kabul Tarihi: 25 Mayıs 2017

Öz

Çeşitli antiseptik taşıyıcılarla karıştıııan kalsiyum hidroksitin Enterococcus faecalis üzerindeki antimikrobiyal etkinliği

Amaç: $\mathrm{Bu}$ in vitro çalışmanın amacı farklı antiseptik taşıyıcı kalsiyum hidroksit (KH) kombinasyonlarının Enterococcus faecalis ( $E$. faecalis) ile enfekte kök kanallarındaki antibakteriyel etkinliğini dentin blok modeli kullanarak test etmektir.

Gereç ve Yöntemler: Altmış adet çekilmiş insan dişi örnekleri hazırlandı. Elli-beş tane kök segmenti $E$. faecalis ile 2 hafta boyunca enfekte edildi. Örnekler 5 deney grubuna ayrıldı $(n=10)$ ve şu $\mathrm{KH}$ - antiseptik taşıyıcı karışımları uygulandı: Grup 1, $\mathrm{KH}+$ gliserin - distile su (7:1); Grup 2, $\mathrm{KH}+$ Octenisept; Grup 3, KH + \%2'lik klorheksidin glukonat (CHX); Grup 4, KH + Savlex; Grup 5, $\mathrm{KH}+\% 5.25^{\prime}$ lik sodyum hipoklorit ( $\left.\mathrm{NaOCl}\right)$. Antiseptik-KH karışımları 7 gün boyunca kök kanallarında bekletildi. Beş örnek sterilliği kontrol etmek için (negatif kontrol), beş örnek de pozitif kontrol olarak kullanıldı. Gates glidden frezler $(\# 3,4,5)$ yardımıla kanal duvarlarından elde edilen dentin örnekleri fosfat-tamponlu salin (PBS) ve cam boncuk içeren şişelere aktarıldı ve 30 sn vortekslendi. Bakteri içeren PBS'ye seri dilüsyon yapıldı. Her bir dilüsyondan $25 \mu \mathrm{L}$ halinde damlalar tripton soya agar plakları üzerine ekildi ve $37^{\circ} \mathrm{C}$ 'de 48 saat inkübe edildi. Görünür koloni sayıları incelendi ve $\log _{10}$ değerlerine dönüştürüldü. İstatistiksel analiz için Kruskal-Wallis ve Mann Whitney-U testleri kullanıldı.

Bulgular: Negatif kontrol grubunda bakteri üremesi görülmezken pozitif kontrol grubunun bütün örneklerinde bakteri üremesi gözlemlenmiştir $\left(\log _{10} 3,47 \mathrm{CFU} \mathrm{ml}^{-1}\right)$. Deney grupları arasında istatistiksel olarak anlamlı bir fark bulunmamıştır $(p>0.05) . \mathrm{KH}+\mathrm{CHX}$ ve $\mathrm{KH}+$ Savlex gruplarında $E$. faecalis biyofilmi tamamen elimine edilmiştir.

Sonuç: Savlex, Octenisept ve $\mathrm{NaOCl}$ gibi çeşitli antiseptik ajanlar $\mathrm{KH}$ ile karıştırılarak kullanıldığında kök kanallarından $E$. faecalis'i elimine etmede etkili bulunmuştur.

\section{ANAHTAR KELIMELER}

Antimikrobiyal, E. faecalis, kanal-içi medikament, kök dentini

Bakteriyel kolonizasyon, pulpa ve periapikal doku hastalıklarının kaynağını oluşturmaktadır. ${ }^{1,2}$ Kök kanal tedavisinin en önemli amaçlarından birisi kök kanal

\section{ABSTRACT}

Antimicrobial activity of calcium hydroxide mixed with various antiseptic vehicles on Enterococcus faecalis

Background: The aim of this in vitro study was to test disinfection ability of different new antiseptic vehicle-calcium hydroxide $(\mathrm{CH})$ combinations in root canals infected with Enterococcus faecalis using a dentin block model.

Methods: Sixty extracted human root samples were prepared. Fifty-five root segments were infected with $E$. faecalis for two weeks. Then, the samples were divided into 5 groups $(n=10)$ and following calcium hydroxide and antiseptic vehicle combinations were applied: Group 1, CH + glycerin with distilled water $(7: 1)$; Group 2, CH + Octenisept; Group 3, CH + 2\% chlorhexidine gluconate (CHX), Group 4, $\mathrm{CH}+$ Savlex; Group 5, $\mathrm{CH}+5.25 \%$ sodium hypochlorite ( $\mathrm{NaOCl})$. Antiseptic-calcium hydroxide mixtures were applied for seven days. Five samples were used to check the sterility (negative control) and five samples were used as positive control. Dentin samples were obtained from the walls with gates-glidden burs (\# 3, 4, 5) and transferred to vials with PBS/glass beads and vortexed for $30 \mathrm{sec}$. PBS with resuspended enterococci was then diluted. Droplets of $25 \mu \mathrm{L}$ from each dilution were inoculated on tryptic soy agar plates and incubated at $37^{\circ} \mathrm{C}$ for 48 hour. Visible colonies from appropriated dilutions were counted and transformed to $\log _{10}$. Kruskal-Wallis and Mann Whitney-U test was used for the statistical analysis.

Results: The negative control group remained free of growth, whereas the positive control group showed $\log _{10}$ CFU ml-1 of 3.47 . No significant difference was observed among the test groups $(p>0.05)$. All $E$. faecalis cells were eliminated from the root canals in $\mathrm{CH}+\mathrm{CHX}$ and $\mathrm{CH}+$ Savlex groups.

Conclusion: The present study demonstrated the effectiveness of various antiseptic agents; Savlex, Octenisept, and $\mathrm{NaOCl}$ when used in mixing calcium hydroxide as vehicles in the elimination of E. faecalis from the root-canals.

\section{KEYWORDS}

Antimicrobial, E. faecalis, root canal medicament, root dentin

sisteminde bulunan bütün mikroorganizmaları elimine etmek ya da en azından konak savunmasının üstesinden gelebileceği bir bakteriyel azalma sağlamaktır. ${ }^{3}$

\footnotetext{
${ }^{*}$ Bu çalışma 2010 yullnın temmuz ayında İspanya'nın Barselona eyaletinde düzenlenen 88. Genel IADR Toplantısinda sözlü bildiri olarak sunulmuştur.

${ }^{\alpha}$ Necmettin Erbakan Üniversitesi Diş Hekimliği Fakültesi Endodonti Anabilim Dalı, Konya

$\beta$ Bezmialem Vakıf Üniversitesi Diş Hekimliği Fakültesi Endodonti Anabilim Dalı, İstanbul

${ }^{\gamma}$ Selçuk Üniversitesi Diş Hekimliği Fakültesi Endodonti Anabilim Dalı, Konya
} 
Kök kanallarında yapılan kemomekanik preparasyon, bakteriyel kolonizasyonu belli bir seviyeye kadar azaltsa da dezenfeksiyonu arttırmak için antibakteriyel etkinliği olan bir kanal içi medikament kullanımı gerekli olmaktadır. ${ }^{4}$ Özellikle enfeksiyonun rutin tedaviye dirençli olduğu durumlarda ve ağrı ile süregelen eksudaya bağlı olarak tedavinin tamamlanamadığı durumlarda kanal içi medikasyona olan ihtiyaç artmaktadır. ${ }^{5}$

$\mathrm{Ca}(\mathrm{OH})_{2}$ kimyasal formülüne sahip beyaz, kokusuz bir toz olan kalsiyum hidroksit $(\mathrm{KH})$, sert doku oluşumunu indükleme, makul antimikrobiyal etkinlik ve doku çözücü özellikleriyle endodontide geniş kullanım alanına sahiptir. ${ }^{6}$ Güçlü bir baz olan KH'nin ( $\mathrm{pH} / 12.5-12.8)$ kalsiyum ve hidroksil iyonlarına ayrışmasıyla bu iyonlar antibakteriyel aktiviteyi gerçekleştirir. ${ }^{7}$ Kanal içi medikament olarak sıklıkla tercih edilen $\mathrm{KH}$ aynı zamanda bakteriler için fiziksel bariyer görevi görerek ve bakterilere besin geçişini engelleyerek antibakteriyel etki göstermektedir. ${ }^{8}$ Bystrom ve ark'nın klinik çalışmasında KH ile tedavi edilen kök kanallarında daha az bakteriye rastlandığı ifade edilirken Stevens ve Grossman ${ }^{9}$ da KH'nin mikroorganizma gelişimini engellemede etkili olduğunu bildirmiştir. Başarısız olan kök kanal tedavisi yenileme vakalarından en sık izole edilen tür Enterococcus faecalis olduğundan, ${ }^{2}$ bu bakterinin elimine edilmesi klinik açıdan önem taşımaktadır. Ancak yapılan bazı çalışmalarda KH'nin $E$. faecalis'i elimine etmede yetersiz kaldığı gösterilmiştir. ${ }^{10-12}$ $\mathrm{Bu}$ yüzden, uzun süre etkili ve geniş spektrumlu antimikrobiyal bir karışım elde etmek için KH'nin distile su ya da gliserin yerine çeşitli dezenfeksiyon solüsyonlarıyla karıştırılabileceği önerilmiştir. ${ }^{13}$

Sodyum hipoklorit ( $\mathrm{NaOCl})$, güçlü antibakteriyel aktivitesi ve doku çözücü özelliği gibi klinik etkinliği dolayısıyla endodonti alanında altın standart olarak kabul görmüş bir irrigasyon solüsyonudur. ${ }^{14} \mathrm{Hem}$ kanal içi medikament hem de irrigasyon solüsyonu olarak kullanılan klorheksidin glukonat (CHX) geniş spektrumlu antimikrobiyal ajandır. Oktenidin hidroklorit ve fenoksietanolden oluşan Octenisept (Schülke\&Mayr, Almanya), deri yanıkları ve yara dezenfeksiyonu için kullanılan bir antiseptiktir. Octenisept'in aynı zamanda ağız gargarası olarak da kullanımı mevcuttur. Savlex (Drogsan, Türkiye), içeriğinde \%15 oranında setrimit ve \%1.5 oranında $\mathrm{CHX}$ bulundurur. Savlex genel antiseptik amaçlara yönelik temizleyici olarak kullanılmaktadır.

$\mathrm{Bu}$ in vitro çalışmanın amacı farklı antiseptik taşıyıcı ve $\mathrm{KH}$ kombinasyonlarının $E$. faecalis ile enfekte kök kanallarını dezenfekte etme kabiliyetini dentin blok modeli kullanarak test etmektir. KH (Sultan Chemists, Englewood, ABD) ile karıştırımak üzere değerlendirilen antimikrobiyal ajanlar; gliserin - distile su karışımı (7:1), Octenisept, \%2'lik CHX (Drogsan, Türkiye), Savlex ve \%5.25'lik NaOCl'dir (Çağlayan Kimya, Türkiye).

\section{GEREÇ VE YÖNTEM}

\section{Kök dentini örneklerinin hazırlanması}

Bu çalışmada ortodontik ve periodontal nedenlerle çekilmiş olan 60 adet tek köklü insan dişi kullanıldı. Daha öncesinde kanal tedavisi uygulanan dişler çalışma dışı bırakılmıştır. Diş örnekleri, yüzey dezenfeksiyonunu sağlamak ve organik debrisi uzaklaştırmak amacıyla 7 günden fazla olmayacak şekilde \%1.3'lük $\mathrm{NaOCl}$ solüsyonunda bekletildi. Periodontal kretuar yardımıyla diş yüzeylerindeki diş taşları uzaklaştırıldı. Kökün apikal $3 \mathrm{~mm}$ 'lik kısmı ve dişin kuronu su soğutması altında döner elmas separe ile kesilerek uzaklaştırıldı. Böylelikle $6 \mathrm{~mm}$ uzunluğunda standart kök örnekleri elde edildi. Kök kanal enstrümentasyonu için Hedström eğeleri (Mani, Inc. Japonya) kullanıldı ve apikal \#55 boyutuna kadar genişletildi. Kök kanalları her bir eğe arasında $10 \mathrm{ml} \% 1.3$ 'lük $\mathrm{NaOCl}$ ile yıkandı. Kök kanal enstrümentasyonu tamamlandıktan sonra 10 ml \%17'lik EDTA ile kök kanalları yıkandı. Son olarak da irrigant artıklarını uzaklaştırmak için $20 \mathrm{ml}$ steril fizyolojik salin solüsyonu ile kanallar yıkandı. Sonrasında kök örnekleri steril fosfat tamponlanmış çözelti (PBS, pH=7,2, Sigma-Aldrich, St. Louis, MO, ABD) içeren test tüplerine yerleştirildi ve $121^{\circ} \mathrm{C}$ 'de 40 dakika otoklavda steril edildi. Her bir steril test örneği $2 \mathrm{ml}$ Tripton soya besiyerinde (TSB) (Biomérieux, Marcy-L'etoile, Fransa) sterilliği kontrol etmek için $37^{\circ} \mathrm{C}$ 'de 24 saat inkübe edildi.

\section{Kök örneklerinin enfekte edilmesi}

$\mathrm{Bu}$ çalışmada Enterococcus faecalis'in klinik suşu (A197A) kullanıldı. Bakteri kültürü, katı besi yeri olan Tripton soy agar (TSA) (Biomérieux, Marcy-L'etolle, Fransa) üzerine ekildi ve $37^{\circ} \mathrm{C}$ 'de 24 saat boyunca inkübe edildi. TSA üzerinde gelişim gösteren koloniler TSB içerisine inoküle edildi.

Elde edilen $E$. faecalis süspansiyonunun optik yoğunluğu spektrofotometrik olarak $\left(\mathrm{OD}_{600}\right)=0.6$ olacak şekilde ayarland. Dişler, rastgele beş deney $(n=10)$ ve iki kontrol grubuna ayrıldı $(n=5)$. Negatif kontrol grubuna ait olan 5 örnek sterilliği kontrol etmek için kullanıldı ve örneklemeden önce 7 gün boyunca steril PBS içerisinde bekletildi.

Elli-beş kök örneği $E$. faecalis suşu ile $37^{\circ} \mathrm{C}$ 'de 2 hafta boyunca inkübe edildi. Enfekte etme işlemi boyunca, bakteri medyası tazelendi ve aynı optik yoğunluğa ayarlanmış olan yeni bakteri süspansiyonu gün aşırı tüplere yerleştirildi. Bakteri kültürünün saflığı, TSA plakları üzerindeki koloni morfolojisi ve hücresel karakteristiklerinin kontrol edilmesiyle teyit edildi. 


\section{Kanal içi medikamentlerin uygulanması}

Bakteri ile kontaminasyon periyodunun ardından, her bir kök kanalı $10 \mathrm{ml}$ steril salin ile yıkandı ve steril kağıt konlarla kurulandı. Aşağıdaki deney medikamentleri steril lentülo yardımıyla kanallar tamamen dolana kadar kanal lümenlerine uyguland;;

Grup 1: $\mathrm{KH}+$ gliserin - distile su $(7 \mathrm{kIsım}$ gliserin - $1 \mathrm{kısım}$ distile su) ${ }^{15}$

Grup 2: $\mathrm{KH}+$ Octenisept

Grup 3: $\mathrm{KH}+\% 2 \mathrm{CHX}$

Grup 4: $\mathrm{KH}+$ Savlex

Grup 5: $\mathrm{KH}+\% 5.25 \mathrm{NaOCl}$

Pozitif kontrol: Medikament uygulanmamış enfekte dişler

Negatif kontrol: Medikament uygulanmamış steril dişler

Çalışmada kullanılan $\mathrm{KH}$ tozu ve antiseptik karışımlarının oranları Tablo 1'de verilmiştir. Medikamentler hazırlanırken KH'nin tüm taşıyıcı solüsyonlar içerisinde tam çözünmesi sağlanmış ve homojen bir kıvam elde edilmiştir. Örneklerin apikal ve servikal yüzeyleri steril alüminyum folyo ile kaplandı ve nemli ortamda $37^{\circ} \mathrm{C}$ 'de 7 gün boyunca inkübe edildi.

Tablo 1.

Test medikamentlerinin içerikleri

\begin{tabular}{|lcc|}
\multicolumn{1}{c}{ Gruplar } & $\begin{array}{c}\text { Kalsiyum Hidroksit } \\
\text { tozu ağırlığı }\end{array}$ & $\begin{array}{c}\text { Taşıуıcı hacmi } \\
5.5 \mathrm{ml} \text { distile su } \\
/ 3.89 \mathrm{ml} \\
\text { gliserin }\end{array}$ \\
\hline $\mathrm{KH}+$ gliserin-distile su & $5.36 \mathrm{gr}$ & $1.86 \mathrm{ml}$ \\
\hline $\mathrm{KH}+$ Octenisept & $1.50 \mathrm{gr}$ & $1.86 \mathrm{ml}$ \\
\hline $\mathrm{KH}+\% 2 \mathrm{CHX}$ & $1.50 \mathrm{gr}$ & $1.86 \mathrm{ml}$ \\
\hline $\mathrm{KH}+$ Savlex & $1.50 \mathrm{gr}$ & $1.86 \mathrm{ml}$ \\
\hline $\mathrm{KH}+\% 2.5 \mathrm{NaOCl}$ & $1.50 \mathrm{gr}$ & \\
\hline
\end{tabular}

\section{Örnekleme işlemi}

Kanala uygulanan medikamentler $10 \mathrm{ml}$ steril salinle yıkanarak uzaklaştııılı. Dentin örnekleri, aseptik koşullar altında kanal duvarlarından gates-glidden frezler $(\# 3,4,5)$ yardımıyla elde edildi. Örnekleme esnasında gates-glidden frezler kök örneklerinin dış yüzeyine temas ettirilmedi. İnce dentin talaşları, içinde PBS bulunan cam şişelere aktarıldı ve şişeler 30 sn vortekslendi. Bakteri içeren PBS 10 kat seyreltildi. Her bir paralel dört dilüsyondan $25 \mu \mathrm{L}$ hacminde damlalar TSA üzerine ekildi. TSA plakları $37^{\circ} \mathrm{C}$ 'de 48 saat inkübe edildi ve koloni oluşumu incelendi. Koloni oluşturan birim sayısı (CFU $\mathrm{mL}^{-1}$ ) hesaplandı ve $\log _{10}$ değerlerine dönüştürüldü. Deneyin bakteri saptama limiti 50 CFU/ml'ydi.

\section{Taramalı elektron mikroskobu (SEM)}

Her bir test grubundan ve kontrol grubundan birer adet ilave örnek $E$. faecalis ile enfekte edildi ve yukarıda tariflenen uygulamalara tabi tutuldu. Örnekler \%2.5'luk gluteraldehit solüsyonu içinde fikse edildi ve SEM cihazı (EVO LS10, Zeiss, Oberkochen, Almanya) altında incelendi. SEM görüntüleri $3000 \times$ ve $10.000 \times$ büyütmelerde alındı.

\section{İstatistiksel analiz}

İstatistiksel analiz $\log _{10}$ değerleri üzerinde gerçekleştirildi. Veriler, IBM SPSS Statistics V19 programı kullanılarak analiz edildi. Veriler normal dağılım göstermediği için parametrik olmayan testler kullanıldı. Gruplar arasında fark olup olmadığını belirlemek amacıyla Kruskal-Wallis, farklıı̆ı̆ hangi gruptan kaynaklandığını tespit etmek için Mann-Whitney testi kullanıldı. İstatistiksel analiz, \%5 anlamllık seviyesinde yapılmıştır.

\section{BULGULAR}

Pozitif kontrol grubundaki bütün örneklerde agar plaklar üzerinde enterokok kolonilerinin gelişim gösterdiği gözlenirken negatif kontrol grubu örneklerinde bakteri üremesi gözlenmemiştir (Resim 1). Deney grupları arasında istatistiksel olarak anlamlı bir fark bulunmamıştır $(P>0.05)$. $\mathrm{KH}+$ Savlex ve $\mathrm{KH}+\% 2 \mathrm{CHX}$ gruplarında enterokok üremesi gözlenmemiştir. Deney gruplarındaki pozitif ve negatif kültür örneklerinin sayısı Tablo 2'de verilmiştir.

Tablo 2.

\section{Test medikamentlerinin içerikleri}

\begin{tabular}{|lcccc|}
\hline \multicolumn{1}{|c}{ Gruplar } & $\mathbf{n}$ & $\begin{array}{c}\text { Negatif } \\
\text { kültür } \\
\text { sayısı }\end{array}$ & $\begin{array}{c}\text { Pozitif } \\
\text { kültür } \\
\text { sayısı }\end{array}$ & $\begin{array}{c}\text { Log }_{10} \mathrm{CFU} \\
\text { Ort } \pm \mathrm{SS}\end{array}$ \\
\hline $\mathrm{KH}+$ gliserin-distile & 10 & 9 & 1 & $0.16 \pm 0.51$ \\
$\mathrm{su}$ & 10 & 9 & 1 & $0.16 \pm 0.51$ \\
\hline $\mathrm{KH}+$ Octenisept & 10 & 10 & 0 & $0 \pm 0$ \\
\hline $\mathrm{KH}+\% 2 \mathrm{CHX}$ & 10 & 10 & 0 & $0 \pm 0$ \\
\hline $\mathrm{KH}+$ Savlex & 10 & 9 & 1 & $0.21 \pm 0.66$ \\
\hline $\mathrm{KH}+\% 2.5 \mathrm{NaOCl}$ & 5 & 0 & 5 & $3.47 \pm 0.57$ \\
\hline Pozitif Kontrol & 5 & 5 & 0 & $0 \pm 0$ \\
\hline Negatif Kontrol & & & & \\
\hline
\end{tabular}



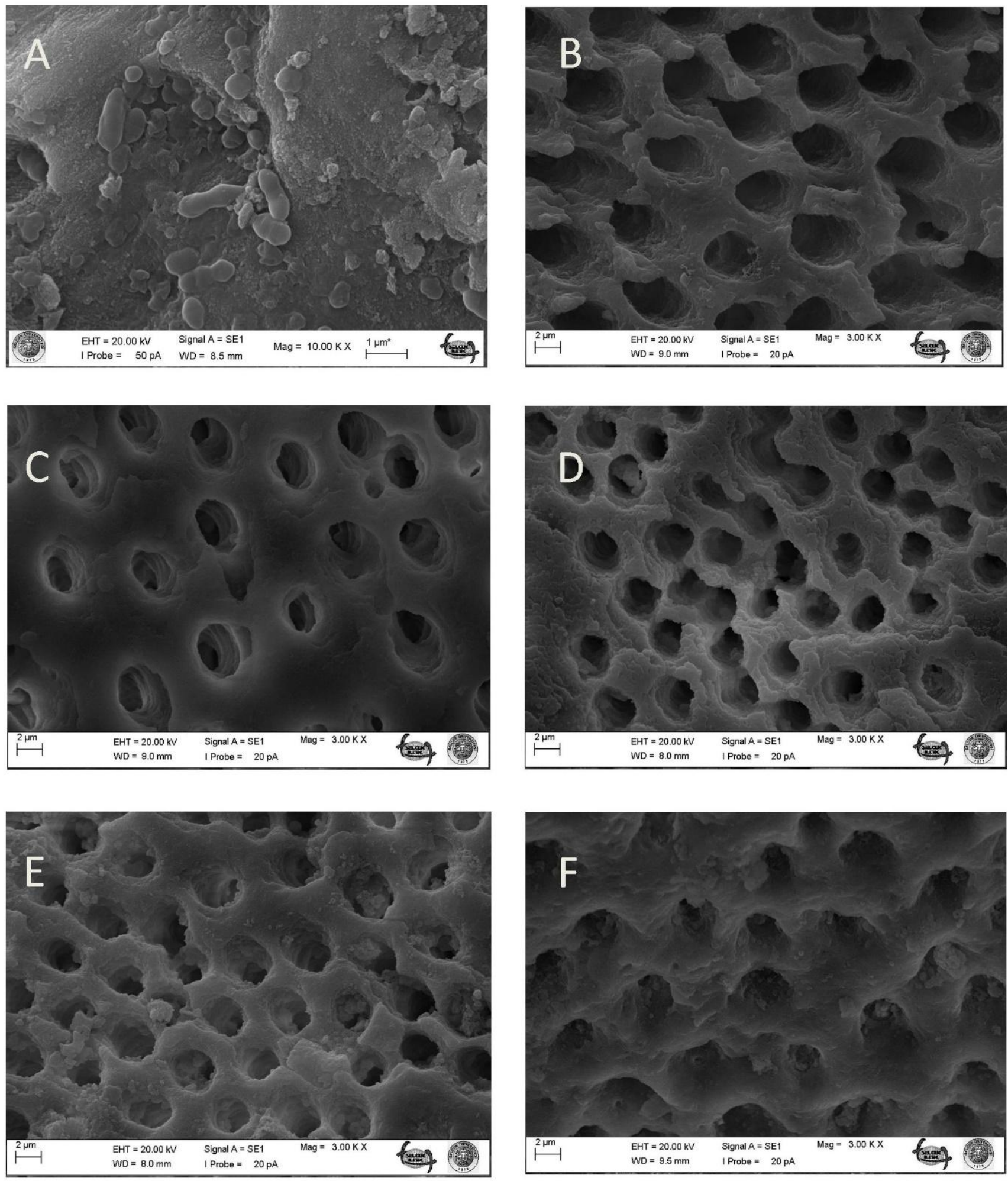

Resim 1.

A) İki hafta enfekte etme periyodundan sonra kök kanal duvarlarındaki E. faecalis kolonizasyonunu gösteren SEM görüntüsü (10.000× büyütme) Test medikamentleri;

B) $\mathrm{KH}+$ gliserin-distile su

C) $\mathrm{KH}+$ Octenisept

D) $\mathrm{KH}+\% 2 \mathrm{CHX}$

E) $\mathrm{KH}+$ Savlex

F) $\mathrm{KH}+\% 5.25 \mathrm{NaOCl}$ uygulanan kök kanal duvarlarının SEM görüntüsü (3000× büyütme) 


\section{TARTIŞMA}

In vitro çalışmalarda, mikroorganizmaların antibakteriyel ajanların etkisinden korunabildiği klinik durumu oluşturmak oldukça güçtür. Haapasalo \& Ørstavik ${ }^{10}$ tarafından 1987 yllında tarif edilen yöntem ile klinik durum iyi bir şekilde taklit edilebilmektedir. Bu yöntemde bazı değişiklikler yapılarak bu çalışmada kullanılmıştır. Bir dezavantaj olarak, kök kanal morfolojisi, dentinin dansitesi, dentinin kalsifikasyon derecesi, dentin tübülü içeriği gibi değişkenler bu modelde standardizasyonu güçleştirmektedir. ${ }^{16} \mathrm{Bu}$ çalışmada kullanılan koloni sayma metodu, çeşitli koşullar altında bölünebilme yeteneğine sahip olan ve hayatta kalabilen mikroorganizmalar ile ilgili bilgi sunmaktadır. ${ }^{17}$ Fakat dentin tübüllerinde canlı olarak kalan ama kültüre edilemeyen bakteriler de bulunabilir. $\mathrm{Bu}$ durum göz önüne alındığında vital boyama yöntemlerinin daha avantajlı olduğu söylenebilir. Dentin blok modeline alternatif olabilecek ve yaygın kullanılan yöntemlerden birisi olan agar difüzyon metodunda bakteri ve test maddesi arasındaki direk etkileşim değerlendirilir. Agar difüzyon metodunda mikrobiyal inhibisyon zonunun oluşması, test edilen maddenin çözünürlüğü ve agar içerisine diffüze olabilme yeteneğine bağlıdır. ${ }^{18}$ Dentin ve dentin komponentlerinin kök kanal medikamentlerinin antimikrobiyal etkinliğini inhibe ettiğ $i^{19}$ düşünüldüğünde dentin blok modelinin bu çalışma için daha uygun olduğu görülmektedir.

Başarısız olmuş kanal tedavili dişlerde $E$. faecalis'in sıklıkla izole edilmesi, bu türün ısrarcı apikal periodontitisin patogenezinde ve hastalığın süregelmesinde önemli rol oynadığına işaret etmektedir. $^{2} E$. faecalis'in kök kanalında bu denli ısrarcı kalabilmesini sağlayan özelliği, endodontik tedavi esnasında kullanılan geleneksel antimikrobiyal ajanlara (KH'nin alkalen ph gibi özelliklerine) direnip canlılığını devam ettirebilmesidir. ${ }^{20}$

KH'nin antibakteriyel aktivite sergilemesi aköz ortama hidroksil iyon salımı yapmasına bağlıdır. Oldukça reaktif olan hidroksil iyonları, lipidler, proteinler ve nükleik asitlerle hızlıca birleşerek bakterileri elimine edebilir. $\mathrm{KH}$, bakterilerin sitoplazmik membranına hasar vererek, lipid peroksidasyonu ve protein denatürasyonu yaparak ya da bakteri DNA'sına zarar vererek etki gösterir. ${ }^{21,22} \mathrm{Bu}$ etki mekanizması sonucu bakteri ölümü gerçekleşmektedir. KH'nin kimyasal olarak ayrışması medikamentin taşıyıcısı kadar ortamın bileşenlerine, kalitesine ve tamponlama etkisine de bağlıdır. ${ }^{23}$ Medikamentin taşıyıcısı iyonik ayrışma hızında ve dezenfeksiyon sürecinde önemli rol oynar. ${ }^{24}$

KH'nin alkalen özelliğinin dentinin derinliklerine ulaşmasının kanal içi medikasyonun başarısını arttıracağı bildirilmiştir. ${ }^{15} \mathrm{Bu}$ durumda, KH'nin yüksek pH'sını dentinin derinliğine en iyi taşıyan araç bakteriyi öldürmede daha etkili olacaktır. Alaçam ve $\operatorname{ark}^{15}$ 'nın çalışmasında $\mathrm{KH}$ gliserin - distile su kombinasyonunun uygulandığı dişlerde dentinin farklı derinliklerinde pH'ın daha yüksek olduğu gösterilmiştir. Bu nedenle Alaçam ve ark $^{15}$ tarafından tarif edildiği şekilde çalışmamızda gliserine distile su ilave edilmiştir. Çalışmamızın bulguları bu karışımın E. faecalis'i bir hafta içinde öldürebildiğini göstermektedir.

Octenisept, geniş spektrumlu antimikrobiyal aktivitesi olan bir antiseptiktir. ${ }^{25}$ Günümüze kadar bu molekül ağız gargarası, ${ }^{26}$ yanıklar için dezenfektan ${ }^{27}$, 28 ve müköz membran antiseptiği ${ }^{29}$ olarak kullanılmışıı. Karsinojenik, mutajenik olmaması ve bakterisidal etki göstermesi gibi özellikleri dolayısıyla kök kanal irrigasyon solüsyonu olarak kullanımı önerilmiştir. ${ }^{30}$ Çalışmamızın sonuçlarına göre $\mathrm{KH}+$ Octenisept grubu $\mathrm{KH}+$ gliserin-distile su kombinasyonuyla benzer antibakteriyel etkinlik sergilemiştir. Yakın zamanda yapılan ve mikrobiyolojik olarak gutta-perka dezenfektanlarını değerlendiren bir çalışmada Octenisept ve \%2.5'luk $\mathrm{NaOCl}$ arasında anlamlı bir fark bulunmamıştır. ${ }^{31}$ Tirali ve $\operatorname{ark}^{32} \mathrm{KH}$ 'yi Octenisept ile karıştırmanın $E$. faecalis üzerindeki antibakteriyel etkinliğini artırdığını fakat antifungal etkinliğini değiştirmediğini rapor etmiştir.

CHX, çok sayıda gram-pozitif ve gram negatif bakteriye karşı bakterisid etki gösterir. ${ }^{33,}{ }^{34}$ Pozitif yüklü hidrofobik ve lipofilik bir molekül olan $\mathrm{CHX}$ bakteri hücre membranındaki fosfolipid ve lipopolisakkaritlerin negatif yüklü fosfat gruplarıla tepkimeye girer. $^{23} \mathrm{CHX}$ bu şekilde bakterinin osmotik dengesini bozarak ve hücre duvarının geçirgenliği arttırarak antimikrobiyal etkisini gösterir.

Savlex (setrimit içeren klorheksidin) gibi yüzey aktif maddesi eklenmiş klorheksidin dezenfektan solüsyonları piyasada bulunmaktadır. Bu çalışmada KH'nin \%2'lik CHX ya da Savlex ile kombinasyonu $E$. faecalis üzerinde iyi antimikrobiyal aktivite göstermiştir ve 7 günlük medikament uygulamasından sonra kök kanallarındaki bakteriyi tamamen elimine etmiştir. Savlex'in sadece CHX'e nazaran $E$. faecalis'i daha hızlı bir şekilde öldürdüğü daha önce yapılan bir çalışmada bildirilmiştir. ${ }^{35}$ Çalışmamızın sonuçlarına bakarak setrimit, $\mathrm{CHX}$ ve KH'nin sinerjistik bir aktivite gösterdiğini söyleyebiliriz. Haenni ve $\operatorname{ark}^{36}$ tarafından yapılan agar difüzyon çalışmasında $\mathrm{KH}$ tozunu \%0.5'lik $\mathrm{CHX}$ ile karıştımanın ilave bir antimikrobiyal etki sergilemediği gösterilmiştir. Benzer şekilde başka bir çalışmada CHX'in E. faecalis'e karşı etkinliğinin süspansiyondaki çözünmemiş $\mathrm{KH}$ tozu dolayısıyla engellendiği bildirilmiştir. ${ }^{37} \mathrm{Bu}$ durum, $\mathrm{pH}$ 10'un üzerinde olduğunda $\mathrm{CHX}$ 'in deprotonasyona uğraması, sonrasında $\mathrm{CHX}$ ve bakteri yüzeyindeki etkileşimin engellenmesi ile açıklanmıştır. ${ }^{38}$ Ancak 
dentinin tamponlama etkisi düşünüldüğünde, hidroksil iyonu KH'den ayrıştıkça $\mathrm{pH}$ düşecek, $\mathrm{CHX}$ yeniden protonlanacak ve dentin tübüllerinde bakterisidal etkisini yeniden kazanacaktır. ${ }^{39}$

$\mathrm{NaOCl}$ güçlü antimikrobiyal ${ }^{40}$ ve organik doku çözücü özellikleri ile en yaygın kullanılan endodontik irrigasyon solüsyonudur. ${ }^{14}$ Düşük maliyeti, kolay ulaşılabilirliği ve uzun raf ömrü NaOCl'nin diğer avantajları arasında sayılabilir. ${ }^{41}$ Ancak periapikal dokular ile temasa geçtiğinde sitotoksik etki göstermesi NaOCl'nin en istenmeyen özelliğidir. Çalışmamızın bulguları $\mathrm{KH}+$ $\mathrm{NaOCl}$ kombinasyonunun iyi antibakteriyel aktivite sergilediğini göstermektedir. Farklı irrigasyon solüsyonlarıyla $\mathrm{KH}$ karışımlarının kimyasal ve antimikrobiyal özelliklerinin araştırıldığı bir çalışmada $\mathrm{KH}$ $+\mathrm{NaOCl}$ karışımının daha az hidroksil iyonu saldığı, her ne kadar agar difüzyon testinde çok etkili bulunmasa da bu karışımın en ümit vaadedici kombinasyon olduğu bildirilmiştir. ${ }^{36}$ Yine başka bir araştırmada, çalışmamızın bulgularıyla paralel olarak $\mathrm{KH}+\% 0.5 \mathrm{NaOCl}$ karışımının dentin bloklarını 24 saatte tamamen dezenfekte ettiği bildirilmiştir. ${ }^{39}$

\section{SONUÇLAR}

$\mathrm{Bu}$ çalışmanın sonuçları Savlex, Octenisept ve $\mathrm{NaOCl}$ gibi çeşitli antiseptik ajanların $\mathrm{KH}$ tozu ile karıştıılarak kullanıldıklarında kök kanallarından $E$. faecalis'in elimine edilmesinde etkili olduğunu desteklemektedir. Bu medikamentlerle ilgili ileri klinik çalışmalara intiyaç vardır.

\section{Teşekkür}

Yazarlar Doç. Dr. Serhan Akman'a istatistiksel analizdeki katkılarından dolayı teşekkür eder. 


\section{KAYNAKLAR}

1. Kakehashi S, Stanley HR, Fitzgerald RJ. The effects of surgical exposures of dental pulps in germ-free and conventional laboratory rats. Oral Surg Oral Med Oral Pathol 1965; 20: 340-9.

2. Sundqvist G, Figdor D, Persson S, , Sjögren U. Microbiologic analysis of teeth with failed endodontic treatment and the outcome of conservative re-treatment. Oral Surg Oral Med Oral Pathol Oral Radiol Endod 1998; 85: 86-93.

3. Siqueira JF, Jr., Rocas IN. Clinical implications and microbiology of bacterial persistence after treatment procedures. J Endod 2008; 34: 1291301 e1293.

4. Bystrom A, Claesson R, Sundqvist G. The antibacterial effect of camphorated paramonochlorophenol, camphorated phenol and calcium hydroxide in the treatment of infected root canals. Endod Dent Traumatol1985; 1: 170-5.

5. Spangberg L. Intracanal medication. Endodontics 1994; 4: 627-40.

6. Nerwich A, Figdor D, Messer HH. Ph changes in root dentin over a 4-week period following root canal dressing with calcium hydroxide. J Endod 1993; 19: 302-6.

7. Hermann B. Calcium hydroxid als mittelzurn, behandeln und fullen von wurzelkanalen [thesis]. Germany: University of Würzburg; 1920.

8. Siqueira JF, Jr., Lopes HP. Mechanisms of antimicrobial activity of calcium hydroxide: A critical review. Int Endod J 1999; 32: 361-9.

9. Stevens RH, Grossman LI. Evaluation of the antimicrobial potential of calcium hydroxide as an intracanal medicament. J Endod 1983; 9: 372-4.

10. Haapasalo $M$, Orstavik D. In vitro infection and disinfection of dentinal tubules. J Dent Res 1987; 66: 1375-9.

11.Safavi KE, Spangberg LS, Langeland K. Root canal dentinal tubule disinfection. J Endod 1990; 16: $207-10$.

12.Siqueira JF, Jr., de Uzeda M. Disinfection by calcium hydroxide pastes of dentinal tubules infected with two obligate and one facultative anaerobic bacteria. J Endod 1996; 22: 674-6.

13.Waltimo TMT, Orstavik D, Siren EK, Haapasalo MP. In vitro susceptibility of candida albicans to four disinfectants and their combinations. Int Endod J 1999; 32: 421-9.

14. Mutluay AT, Mutluay M. Sodyum hipoklorit: Endodontide kullanım alanları. Atatürk Üniv Diş Hek Fak Derg 2015; 25: 258-65.

15.Alacam T, Yoldas HO, Gulen O. Dentin penetration of 2 calcium hydroxide combinations. Oral Surg Oral Med Oral Pathol Oral Radiol Endod 1998; 86: 469-72.
16.Abdullah M, Ng YL, Gulabivala K, Moles DR, Spratt DA. Susceptibilties of two enterococcus faecalis phenotypes to root canal medications. J Endod 2005; 31: 30-6.

17.de Lucena JM, Decker EM, Walter C, Boeira LS, Löst C, Weiger R. Antimicrobial effectiveness of intracanal medicaments on enterococcus faecalis: Chlorhexidine versus octenidine. Int Endod J 2013; 46: 53-61.

18. Tirali RE, Bodur H, Sipahi B, Sungurtekin E. Evaluation of the antimicrobial activities of chlorhexidine gluconate, sodium hypochlorite and octenidine hydrochloride in vitro. Aust Endod $\mathrm{J}$ 2013; 39: 15-8.

19. Haapasalo HK, Siren EK, Waltimo TM, Ørstavik D, Haapasalo MP. Inactivation of local root canal medicaments by dentine: An in vitro study. Int Endod J 2000; 33: 126-31.

20.Orstavik D, Haapasalo M. Disinfection by endodontic irrigants and dressings of experimentally infected dentinal tubules. Endod Dent Traumatol 1990; 6: 142-9.

21.Freeman BA, Crapo JD. Biology of disease: Free radicals and tissue injury. Lab Invest 1982; 47: 41226.

22.Siqueira Junior JF. Tratamento das infecções endodônticas. Tratamento das infecções endodônticas. Medsi; 1997.

23. Athanassiadis B, Abbott PV, Walsh LJ. The use of calcium hydroxide, antibiotics and biocides as antimicrobial medicaments in endodontics. Aust Dent J 2007; 52: S64-S82.

24.Gomes BPFdA, Ferraz CCR, Vianna ME, Rosalen $\mathrm{PL}$, Zaia AA, Teixeira FB et al. In vitro antimicrobial activity of calcium hydroxide pastes and their vehicles against selected microorganisms. Braz Dental J 2002; 13: 155-61.

25.Sedlock DM, Bailey DM. Microbicidal activity of octenidine hydrochloride, a new alkanediylbis[pyridine] germicidal agent. Antimicrob Agents Chemother.1985; 28: 786-90.

26. Slee AM, O'Connor JR. In vitro antiplaque activity of octenidine dihydrochloride (win 41464-2) against preformed plaques of selected oral plaque-forming microorganisms. Antimicrob Agents Chemother 1983; 23: 379-84.

27. Buhrer C, Bahr S, Siebert J, Wettstein R, Geffers C, Obladen M. Use of 2\% 2-phenoxyethanol and $0.1 \%$ octenidine as antiseptic in premature newborn infants of 23-26 weeks gestation. J Hosp Infect 2002; 51: 305-7. 
28. Kramer A, Roth B, Muller G, Rudolph P, Klöcker N. Influence of the antiseptic agents polyhexanide and octenidine on $\mathrm{fl}$ cells and on healing of experimental superficial aseptic wounds in piglets. A double-blind, randomised, stratified, controlled, parallel-group study. Skin Pharmacol Physiol 2004; 17: 141-6.

29. Heeg P. Antisepsis of mucous membranes--current status and aspects of future development. Z Gesamte Hyg 1990; 36: 83-6.

30. Tirali RE, Turan Y, Akal N, Karahan Z C. In vitro antimicrobial activity of several concentrations of naocl and octenisept in elimination of endodontic pathogens. Oral Surg Oral Med Oral Pathol Oral Radiol Endod 2009; 108: E117-E20.

31.Sahinkesen G, Oktay EA, Er O, Koçak MM, Kiliç A. Evaluation of residual antimicrobial effects and surface changes of gutta-percha disinfected with different solutions. J Contemp Dent Pract 2011; 12: 47-51.

32.Tirali RE, Gulsahi K, Cehreli SB, Karahan ZC, Uzunoğlu E, Elhan A. Antimicrobial efficacy of octenidine hydrochloride, mtad and chlorhexidine gluconate mixed with calcium hydroxide. J Contemp Dent Pract 2013; 14: 456-60.

33. Davies GE, Francis J, Martin AR, Rose FL, Swain G. 1:6-di-4'-chlorophenyldiguanidohexane (hibitane); laboratory investigation of a new antibacterial agent of high potency. Br J Pharmacol Chemother 1954; 9: 192-6.

34. Lawrence C. Antimicrobial activity, in vitro, of chlorhexidine. Journal of the American Pharmaceutical Association 1960; 49: 731-4.

35.Portenier I, Waltimo T, Orstavik D, Haapasalo M. Killing of enterococcus faecalis by mtad and chlorhexidine digluconate with or without cetrimide in the presence or absence of dentine powder or bsa. J Endod 2006; 32: 138-41.

36. Haenni S, Schmidlin PR, Mueller B, Sener B, Zehnder M. Chemical and antimicrobial properties of calcium hydroxide mixed with irrigating solutions. Int Endod J 2003; 36: 100-5.

37.Siren EK, Haapasalo MP, Waltimo TM, Ørstavik D. In vitro antibacterial effect of calcium hydroxide combined with chlorhexidine or iodine potassium iodide on enterococcus faecalis. Eur J Oral Sci 2004; 112: 326-31.

38.Jones DS, Brown AF, Woolfson AD, Dennis AC, Matchett LJ, Bell SE. Examination of the physical state of chlorhexidine within viscoelastic, bioadhesive semisolids using raman spectroscopy. J Pharm Sci 2000; 89: 563-71.

39.Zehnder M, Grawehr M, Hasselgren G, Waltimo T. Tissue-dissolution capacity and dentin-disinfecting potential of calcium hydroxide mixed with irrigating solutions. Oral Surg Oral Med Oral Pathol Oral Radiol Endod 2003; 96: 608-13.
40.Bystrom A, Sundqvist G. Bacteriologic evaluation of the effect of 0.5 percent sodium hypochlorite in endodontic therapy. Oral Surg Oral Med Oral Pathol 1983; 55: 307-12.

41.Frais S, Ng YL, Gulabivala K. Some factors affecting the concentration of available chlorine in commercial sources of sodium hypochlorite. Int Endod J 2001; 34: 206-15.

Yazışma Adresi:

Yrd.Doç.Dr.Makbule Bilge AKBULUT

Necmettin Erbakan Üniversitesi

Diş Hekimliği Fakültesi

Endodonti AD

Konya, Türkiye

Tel : +90332 2200026

Faks : +90 3322200045

E-mail: dt.bilge@yahoo.com 